\title{
Molecular characterization of Salt and Drought Tolerant Mutant and Parental Plants by Using RAPD
}

\author{
S. S. Gadakh ${ }^{1 *}$, D. U. Patel ${ }^{2}$ and Diwakar Singh ${ }^{3}$
}

${ }^{1}$ Dept. of Agricultural Botany, College of Agriculture, Nandurbar, Maharashtra (425 412), India

${ }^{2}$ Main Sugarcane Research Station, ${ }^{3}$ Dept. of Plant Molecular Biology and Biotechnology, ASPEE College of Horticulture \& Forestry, Navsari Agricultural University, Navsari, Gujarat (396 450), India

\section{Corresponding Author}

S. S. Gadakh

e-mail: gadakhsuraj@gmail.com

\author{
Article History \\ Manuscript No. AR1739 \\ Received in $27^{\text {th }}$ November, 2016 \\ Received in revised form $16^{\text {th }}$ February, 2017 \\ Accepted in final form $5^{\text {th }}$ April, 2017
}

\begin{abstract}
Present experiments were carried out in 2011 to 2014 at tissue culture laboratory of Main Sugarcane Research Station and Department of Plant Molecular Biology and Biotechnology, Navsari Agricultural University, Navsari to evaluate variability at molecular level between parent and salt and drought tolerant mutant developed by application of selection pressure in tissue culture. Ethyl Methane Sulphonate EMS ( $0.5 \%$ for 2 hours) treated embryogenic calli of sugarcane (Saccharum spp. Complex, cv. Co 99004). Calli were cultured on a selective medium containing $\mathrm{NaCl}(100 \mathrm{mM})$ and PEG $(2 \%)$ for development of salt and drought tolerant plants separately, primer OPK-4 produced maximum 12 bands out of which one was polymorphic. The primer OPK-20 produced 3 monomorphic bands out of total 9 bands. Primer OPK-10 produced maximum polymorphism (100\%) followed by primer OPK-04 (91.67\%), OPK-15 (88.89\%) and OPL-03 (88.89\%). Line 8 had showed maximum genetic variation to the parental plant $(0.543)$ followed by line $10(0.556)$ and line $2(0.565)$. The regenerants of Co 99004 were divided into two clusters, which placed lines 1, 2, 3, 4, 5, 6, 7, 9 and control into first cluster whereas, line 8 and 10 into second cluster. The dendrogram also divided maximum salt tolerant and drought tolerant lines into two clusters suggesting that salt regenerants completely different from drought tolerant lines. Maximum salt and drought tolerant lines placed away from the control supporting the polymorphism revealed by the RAPD profile.
\end{abstract}

Keywords: Sugarcane, in vitro mutagenesis, salt tolerance, drought tolerance, RAPD

\section{Introduction}

Sugarcane is the most important cash crops in India. Improvement in this crop through breeding is handicapped because of the complex flowering behavior under natural day-length conditions in India. The complexity and polygenic nature of salinity tolerance has seriously limited the efforts to develop the tolerant crop variety through conventional breeding practices. Tissue and cell culture techniques provide new methods for deriving genetic variation in relatively shorter duration. The use of plant cell culture techniques has expanded greatly particularly in the improvement of vegetatively propagated crops like sugarcane. In this crop genetic variation can be introduced through somaclonal variation (Heinz and Mee, 1969; Liu et al., 1972). It has been reported that in vitro irradiation and other mutagenic agents increase variation and the level of stress tolerance among regenerants (Chaudhary et al., 1994; Patade et al., 2006).

Somaclonal variation occurs among the callus culture regenerated plants. Cellular and molecular mechanisms behind the variations are mitotic irregularities leading to chromosomal instability, occurrence of gene amplification or deletion, gene deactivation or reactivation of silent genes, transposition and somatic crossing over, DNA methylation in case of epigenetic variation and point mutations. In vitro mutagenesis can be useful if results in addition effects with respect to mutation frequency and mutation spectrum in combination with quicker positive results and no effects on survival and fertility of treated cultures (Patade et al., 2005; Triono et al., 2016).

Detection of variants is of immense importance in order to harvest those for crop improvement. The variants may have genetic or epigenetic basis before early detection is of prime importance. It is rather difficult to detect genetic variation from the morphological features. Among the different molecular techniques, RAPD is widely used to study the variation at DNA level among the variants (Patade et al., 2006; Khaled 2010; Doule et al., 2008; Pandey et al., 2012; Khan et al., 2013). Therefore, in the present study RAPD technology 
used to detect genetic variation present between and among salt and drought tolerant lines and parental line.

\section{Materials and Methods}

Present research carried out at tissue culture laboratory of Main Sugarcane Research Station, N.A.U., Navsari and Department of Plant Molecular Biology and Biotechnology, ASPEE College of Horticulture \& Forestry, N. A. U., Navsari in 2011 to 2014. In vitro mutagenesis technique used to obtain salt and drought tolerant mutants. EMS (0.5\% for 2 hours) treated embryogenic calli of sugarcane (Saccharum spp. Complex, cv. Co 99004). Calli were cultured on a selective medium containing $\mathrm{NaCl}(100 \mathrm{mM})$ for salt tolerance and Polyethelene glycol (PEG 2\%) for drought tolerance. For molecular characterization, two to three week old seedlings of 5 lines from salt stress and 5 lines from drought stress were grown in field used for genomic DNA isolation for Randomly Amplified polymorphic DNA (RAPD).

The reagents and buffers for DNA isolation were prepared as per Sambrook et al. (1989). Total DNA was extracted from the leaves by Cetyl trimethyl ammonium bromide (CTAB) method as described by Khan et al. (2013) with some minor modifications. To estimate the quantity and quality (in terms of protein and RNA contamination) of isolated genomic DNA, spectrophotometry was performed and the data was analyzed using software N.D. (V.3.3.0). DNA (1 $\mu \mathrm{l})$ was loaded in the well of Nanodrop instrument and the concentration of DNA and absorbance at $260 \mathrm{~nm}$ and $280 \mathrm{~nm}$ were measured as well as the A260/A280 ratio was found out automatically by the software. The conversion factor or constant used was 50 for concentration measurement. To check quality of DNA (supercoiled, linear or sheared) and RNA contamination of isolated genomic DNA was run electrophoretically on $0.8 \%$ agarose gel and quality was judged by viewing the image of separated DNA fragments.

The genomic DNA amplified using random 60 primers of OPK and OPL series (Operon Tech., California, USA). PCR reactions for RAPD were carried out in a reaction volume of $25 \mu \mathrm{l}$ using the method given by Rashed et al. (2008) with some modifications.

Data was scored for computer analysis on the basis of the presence or absence of the PCR products. If a product was present in a genotype, it was designated as ' 1 ' and if absent; it was designated as ' 0 '. The data were maintained in the spread sheet format for further analysis. The polymorphism percentage was calculated as per the method suggested by Blair et al. (1999).

Polymorphism information content $(\mathrm{PIC})=2 \mathrm{Pi}(1-\mathrm{Pi})$

Where, $\mathrm{Pi}$ = frequency of occurrence of polymorphic bands in different primers

$$
\text { Polymorphism }(\%)=\frac{X-Y}{X}
$$

Where $\mathrm{X}=$ Total number of bands

$\mathrm{Y}=$ Number of Monomorphic band
The data generated by RAPD were analyzed with the software NTSYSpc version 2.02 .

\section{Results and Discussion}

In present investigation the average concentration of DNA was $508.9 \mathrm{ng} \mathrm{\mu l}^{-1}$ measured by nanodrop spectrophotometer (Table 1). The line 11 showed highest concentration as 617.7 ng $\mu^{-1}$. However, line 3 showed lowest concentration of $432.0 \mathrm{ng} \mathrm{\mu l}^{-1}$. Quantitative analysis of DNA was carried out from uniform working stock dilution of all lines for further PCR analysis.

The quality of DNA was decided by optical density 260:280 ratio. All the lines have optical density (260:280 ratio) between

Table 1: Qualitative and quantitative analysis of genomic DNA using nanodrop spectrophotometer of different sugarcane lines

\begin{tabular}{lcc}
\hline Line no. & $\begin{array}{c}\text { Genomic DNA concentration } \\
\left(\mathrm{ng} \mu \mathrm{l}^{-1}\right)\end{array}$ & $\begin{array}{c}\text { Optical density } \\
260: 280 \text { ratio }\end{array}$ \\
\hline 1. & 569.2 & 1.87 \\
2. & 455.1 & 1.91 \\
3. & 432.0 & 1.95 \\
4. & 472.4 & 1.95 \\
5. & 526.9 & 1.87 \\
6. & 518.4 & 1.88 \\
7. & 507.7 & 1.91 \\
8. & 515.7 & 1.90 \\
9. & 447.2 & 1.98 \\
10. & 535.8 & 1.93 \\
$11(\mathrm{P})$. & 617.7 & 1.88 \\
Average & 508.9 & 1.91 \\
\hline
\end{tabular}

P: Parent; 1-10: Mutant lines

1.87 to 1.98 (Table 1$)$. The integrity of DNA was also confirmed on agarose gel electrophoresis (Plate 1). It showed compact band without RNA contamination. The genetic variability among the in vitro mutagenized and selected sugarcane plants

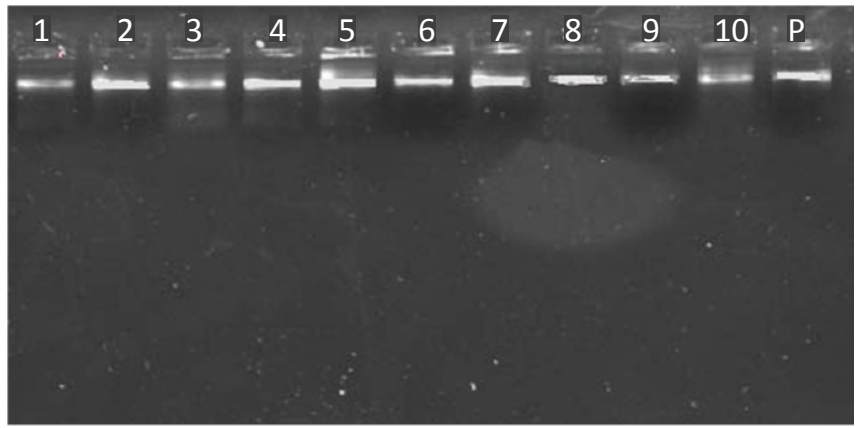

Plate 1: Genomic DNA of sugarcane cv. Co 99004 (1-5=salt tolerant mutant, $6-10=$ Drought tolerant mutant and $\mathrm{P}=$ parent) 
was analyzed using RAPD molecular marker technique. In this study 60 random decamer primer from Operon series (OPK, OPE and OPL) were screened. Out of which those primers which gave maximum polymorphism were selected.

Ten decamers oligonucleotide primers were used for a RAPD analysis. On an average each primer gave nine bands. The amplification products range from $0.1 \mathrm{~Kb}$ to $1 \mathrm{~Kb}$. In genotype Co 99004 (Plate 2, 3, 4 and 5), primer OPK-4

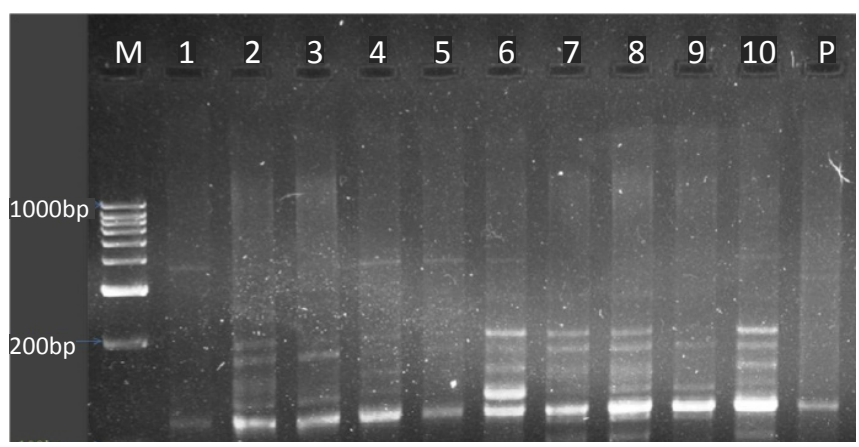

Plate 2: RAPD amplification profile of sugarcane mutants and parent produced by primer OPL-03 (M: 1 kb DNA marker ladder; 1-5: salt tolerant mutant; 6-10: Drought tolerant mutant; P: Parent)

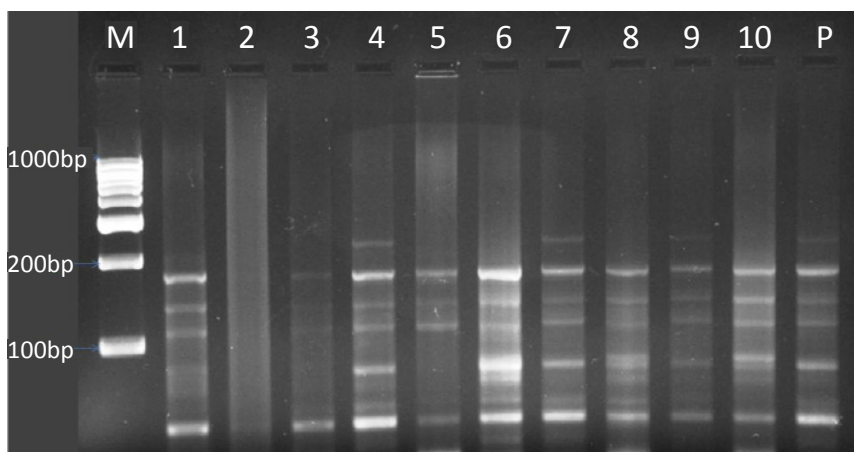

Plate 3: RAPD amplification profile of sugarcane mutants and parent produced by primer OPL-02 (M: 1 kb DNA marker ladder; 1-5: Salt tolerant mutant; 6-10: Drought tolerant mutant; P: Parent)

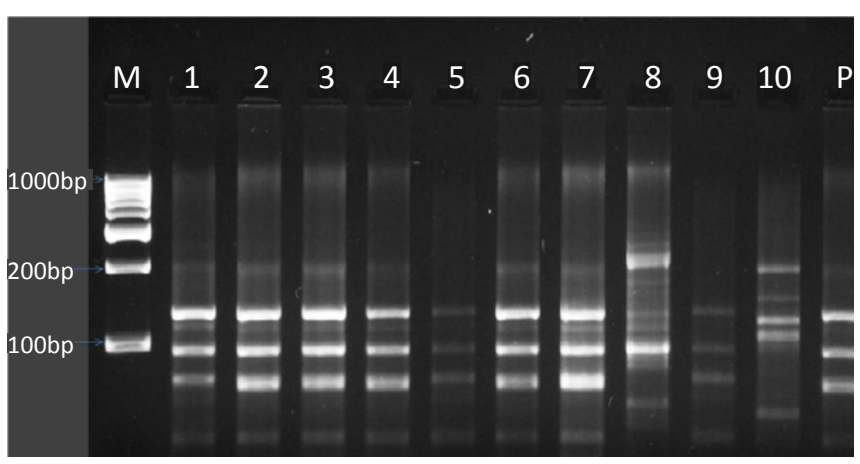

Plate 4: RAPD amplification profile of sugarcane mutants and parent produced by primer OPK-04 (M: 1 kb DNA marker ladder; 1-5: Salt tolerant mutant; 6-10: Drought tolerant mutant; P: Parent)

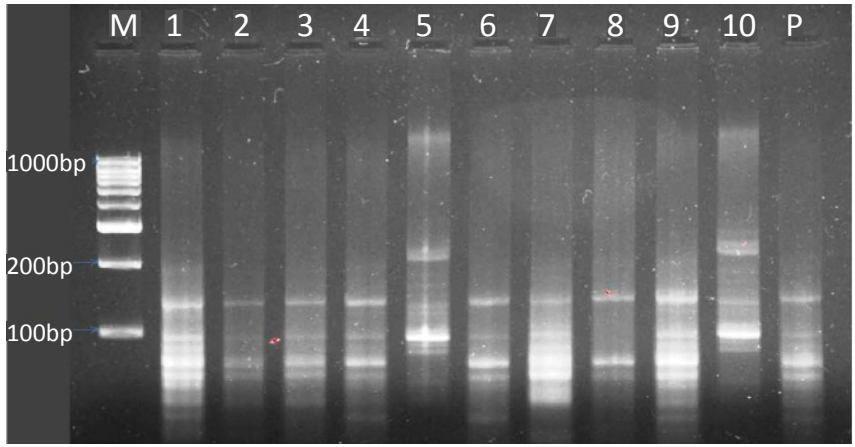

Plate 5: RAPD amplification profile of sugarcane mutants and parent produced by primer OPK-15 ( $\mathrm{M}=1 \mathrm{~kb}$ DNA marker ladder, 1-5=Salt tolerant mutant, 6-10=Drought tolerant mutant and $\mathrm{P}=$ Parent)

produced maximum 12 bands (Table 2 ) out of which one was polymorphic. The primer OPK-20 produced 3 monomorphic bands out of total 9 bands. Primer OPK-10 produced maximum polymorphism (100\%) followed by primer OPK-04 (91.67\%), OPK-15 (88.89\%) and OPL-03 (88.89\%).

\begin{tabular}{lcccccc}
\hline \multicolumn{6}{c}{ Table 2: RAPD polymorphism data of sugarcane cv. Co 99004} \\
\hline SI. No. & PN & TL & PL & ML & P & PIC Value \\
\hline 1. & OPK-03 & 5 & 4 & 1 & 80.00 & 0.7962 \\
2. & OPK-04 & 12 & 11 & 1 & 91.67 & 0.8728 \\
3. & OPK-09 & 10 & 8 & 2 & 80.00 & 0.8788 \\
4. & OPK-10 & 10 & 10 & 0 & 100.00 & 0.8727 \\
5. & OPK-11 & 8 & 7 & 1 & 87.50 & 0.8681 \\
6. & OPK-15 & 9 & 8 & 1 & 88.89 & 0.8737 \\
7. & OPK-18 & 7 & 5 & 2 & 71.43 & 0.8160 \\
8. & OPK-20 & 9 & 6 & 3 & 66.67 & 0.8668 \\
9. & OPL-02 & 10 & 8 & 2 & 80.00 & 0.8923 \\
10. & OPL-03 & 9 & 8 & 1 & 88.89 & 0.8628 \\
Total & & 89 & 75 & 14 & & \\
Mean & & 9 & 8 & 1 & 83.50 & 0.8600 \\
\hline
\end{tabular}

PN: Primer name; TL: Total loci (bands); PL: Polymorphic loci (bands); ML: Monomorphic loci (bands); P: \% Polymorphism

The RAPD profiles revealed genetic polymorphism among selected salt tolerant and drought tolerant lines from the control plant. The data of presence or absent of bands for a particular primer for parent, salt tolerant and drought tolerant lines has been recorded and used for similarity based analysis and Jaccard's coefficient was calculated (Table 3).

The NTSYSpc programme was used to calculate Jaccard's similarity coefficient. The genetic similarity between mother and regenerated plants was an average. Line 8 had showed maximum genetic variation to the control plant (0.543) followed by line $10(0.556)$ and line 2 (0.565). The genetic similarity between control, salt and drought tolerant lines 


\begin{tabular}{|c|c|c|c|c|c|c|c|c|c|c|c|}
\hline & 1 & 2 & 3 & 4 & 5 & 6 & 7 & 8 & 9 & 10 & Control \\
\hline 1 & 1.000 & & & & & & & & & & \\
\hline 2 & 0.485 & 1.000 & & & & & & & & & \\
\hline 3 & 0.585 & 0.684 & 1.000 & & & & & & & & \\
\hline 4 & 0.589 & 0.594 & 0.727 & 1.000 & & & & & & & \\
\hline 5 & 0.567 & 0.414 & 0.585 & 0.625 & 1.000 & & & & & & \\
\hline 6 & 0.542 & 0.544 & 0.557 & 0.732 & 0.493 & 1.000 & & & & & \\
\hline 7 & 0.592 & 0.529 & 0.577 & 0.736 & 0.541 & 0.714 & 1.000 & & & & \\
\hline 8 & 0.485 & 0.438 & 0.470 & 0.528 & 0.435 & 0.591 & 0.621 & 1.000 & & & \\
\hline 9 & 0.620 & 0.514 & 0.548 & 0.671 & 0.627 & 0.627 & 0.722 & 0.514 & 1.000 & & \\
\hline 10 & 0.478 & 0.500 & 0.449 & 0.520 & 0.557 & 0.557 & 0.586 & 0.655 & 0.583 & 1.000 & \\
\hline Control & 0.676 & 0.565 & 0.672 & 0.750 & 0.681 & 0.681 & 0.685 & 0.543 & 0.712 & 0.556 & 1.000 \\
\hline
\end{tabular}

1-5 are salt tolerant mutants; 6-10 are drought tolerant mutants; Control: parent

ranges between 0.414 and 0.750 (Table 3).

The dendrogram constructed by Jaccard's co-efficient of similarity indicated differences among salt tolerant lines, drought tolerant lines and control. The regenerants of Co 99004 were divided into two clusters based on secondary branching, which placed lines 1, 2, 3, 4, 5, 6, 7, 9 and control into first cluster, lines 8 and 10 into second cluster (Figure 1).

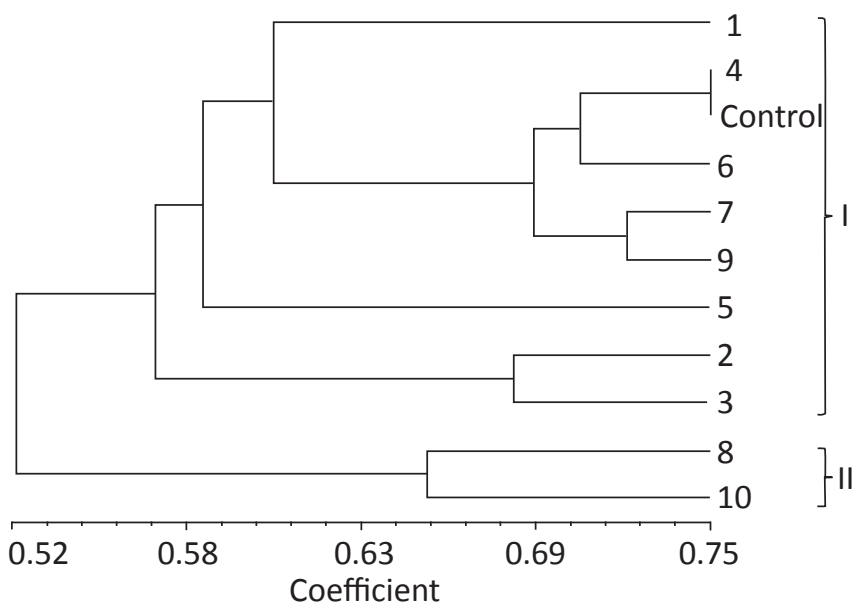

Figure 1: Dendrogram of sugarcane mutants; $1-5$ : Salt tolerant mutant; 6-10: Drought tolerant mutant; Control: Parent

Interestingly the dendrogram also divided maximum salt tolerant and drought tolerant lines into two clusters suggesting that salt regenerants completely different from drought tolerant lines. In lines of cv. Co 99004, parent and line 4 placed together depicting high similarity between them. Maximum salt and drought tolerant lines placed away from the control supporting the polymorphism revealed by the RAPD profile. This suggests that the mutated, salt and drought stressed regenerants are better for selection of the mutants.

At stringent annealing conditions, even slight base change at the primer annealing site can results in presence or absence of loci. It is therefore clear that in vitro mutagenesis and tissue culture conditions have induced varied amount of genetic changes among the selected salt and drought tolerant plants from EMS treated callus cultures. Some bands in RAPD profile are monomorphic indicating the similarity of selected plants to control plants. This may be due to the use of same callus culture under study and most of the genome remains unchanged under in vitro mutagenesis.

The results in the present study are in agreement with detection of genetic variation with RAPD analysis by Patade et al. (2006); Dalvi et al. (2012); Patade et al. (2006) analyzed the variability among the irradiated and non-irradiated salt stress and PEG stress calli using RAPD technique. Dalvi et al. (2012) detected smut resistant mutants developed from EMS treated calli using RAPD analysis.

\section{Conclusion}

RAPD analysis of genetic variation among the in vitro selected drought and salinity tolerant mutants suggest that variation can be detected at the stage of regeneration even before hardening in the green house or planting in field. The technique has proved very sensitive for fingerprinting/ characterization of in vitro selected salt tolerant and drought tolerant plants in sugarcane.

\section{Acknowledgement}

The authors wish to thanks to Head, Department of Plant Molecular Biology and Biotechnology, Navasari Agricultural University, Navsari for providing laboratory facility at the division during course of this investigation.

\section{Reference}

Blair, R.J.R., Morris, J.S., Frith, C.D., Perrett, D.I., Dolan, R.J., 
1999. Dissociable neural responses to facial expressions of sadness and anger. Brain 122, 883-893.

Chaudhary, M.T., Wainwright, S.J., Merrett, M.J., Shah, M., 1994. Salt tolerant of Lucerne (Medicago media Pers.) regenerated from salt selected suspension cultures. Plant Science 98, 97-102.

Dalvi, S.G., Vasekar, V.C., Yadav, A, Tawar, P.N., Dixit, G.B., Theerthaprasad, D., Deshmukh, R.B., 2012. Screening of Promising Sugarcane Somaclones for Agronomic Traits, and Smut Resistance Using PCR Amplification of Inter Transcribed Region (ITS) of Sporisorium scitaminae. Sugar Tech 14(1), 68-75.

Doule, R.B., Kawar, P.G., Devarumath, R.M., Nerkar, Y.S., 2008. Field performance and RAPD analysis for assessment of genetic variation in sugarcane somaclones. Indian Journal of Genetics and Plant Breeding 68(3), 301-306.

Heinz, D.J., Mee, G.W.P., 1969. Plant differentiation from callus tissue of Saccharum species. Crop Science 9, 346-348.

Khaled, K.A.M., 2010. Molecular characterization and genetic similarity of three sugarcane genotypes. Egyptian Journal of Genetics and Cytology 39, 249-257.

Khan, I.A., Bibi, S., Yasmin, S., Khatri, A., Seema, N., 2013. Phenotypic and genotypic diversity investigations in sugarcane for drought tolerance and sucrose content. Pakistan Journal of Botany 45(2), 359-366.

Liu, M.C., Huang, Y.J., Shffl, S.C., 1972. The in-vitro production of plants from several tissues of Saccharum species. Journal of the Agricultural Association of China 77, 52-58.
Pandey, R.N., Singh, S.P., Rastogi, J., Sharma, M.L., Singh, R.K., 2012. Early assessment of genetic fidelity in sugarcane (Saccharum officinarum) plantlets regenerated through direct organogenesis with RAPD and SSR markers. Australian Journal of Crop Science 6(4), 618-624.

Patade, V.Y., Suprrasana, P., Bapat, V.A., Kulkarni, U.G., 2005. Selection for abiotic (salinity and drought) stress tolerance and molecular characterization of tolerant lines in sugarcane. Poster presentation in National Conference on "Biotechnological Aspects towards Cultivation, Utilization and Disease Management of Plants", held at Lal Bahadur Shastri Mahavidyalaya, Dharmabad, Nanded.

Patade, V.Y., Suprasanna, P., Bapat, V.A., 2006. Selection for abiotic (salinity and drought) stress tolerance and molecular characterization of tolerant lines in sugarcane. B.A.R.C. Newsletter, 273.

Rasheed, S.U., Azad, M., Zafar, Y., 2008. Use of radiation and in virto technique for development of salt tolerant mutants in sugarcane and potato. Journal of Genetic Engineering and Biotechnology 80(4), 61-73.

Sambrook, J., Fritsch, E.F., Maniatis, T., 1989. Molecular cloning: A laboratory Manual. II ${ }^{\text {nd }}$ (edn.). Cold Spring Harbour Laboratory. Press, Cold Spring Harbour, N.Y., 1659.

Saputro, T.B., Finariyah, F., Dianawati, S., Sholihah, N.F., Ermavitalini, D., 2016. In vitro selection of Local Maize (Zea mays) on $\mathrm{NaCl}$ Stress and Its Genetic Characterization using RAPD. Biosaintifika 8(3), 343-351. 